\title{
Nerve Growth Factor: Cellular Localization and Regulation of Synthesis
}

\author{
Hans Thoenen, ${ }^{1,2}$ Christine Bandtlow, ${ }^{1}$ Rolf Heumann, ${ }^{1}$ Dan \\ Lindholm, ${ }^{1}$ Michael Meyer, ${ }^{1}$ and Hermann Rohrer ${ }^{1}$
}

Received August 15, 1987; accepted August 30, 1987

KEY WORDS: nerve growth factor; neural crest; sympathetic system; axonal transport; in situ hybridization.

\section{SUMMARY}

1. The role of nerve growth factor (NGF) as a retrograde messenger between peripheral target tissues and innervating sympathetic and neural crest-derived sensory neurons is supported by the observations that (a) the interruption of retrograde axonal transport has the same effects as the neutralization of endogenous NGF by anti-NGF antibodies and (b) the close correlation between the density of innervation by fibers of NGF-responsive neurons and the levels of NGF and mRNA ${ }^{\mathrm{NGF}}$ in their target organs.

2. In situ hybridization experiments have demonstrated that a great variety of cells in the projection field or NGF-responsive neurons is synthesizing NGF, among them epithelial cells, smooth muscle cells, fibroblasts, and Schwann cells.

3. The temporal correlation between the growth of trigeminal sensory fibers into the whisker pad of the mouse and the commencement of NGF synthesis initially suggested a causal relationship between these two events. However, in chick embryos rendered aneural by prior removal of the neural tube or the neural crest, it was shown that the onset of NGF synthesis in the periphery is independent of neurons, and is controlled by an endogenous "clock" whose regulatory mechanism remains to be established.

4. A comparison between NGF synthesis in the nonneuronal cells of the newborn rat sciatic nerve and that in the adult sciatic nerve after lesion provided evidence for the important regulatory role played by a secretory product of

\footnotetext{
${ }^{1}$ Max-Planck-Institute for Psychiatry, Department of Neurochemistry, D-8033 Martinsried, FRG.

${ }^{2}$ To whom correspondence should be addressed.
} 
activated macrophages. The identity of this product is currently under investigation.

\section{INTRODUCTION}

In many parts of the central and peripheral nervous system it has been established that both neuronal and nonneuronal target cells have an important influence on the development and maintenance of innervating neurons (cf. Cowan et al., 1984; Thoenen and Edgar, 1985). For the peripheral sympathetic and neural crestderived spinal sensory neurons, nerve growth factor (NGF) has been identified as the mediator of this retrograde trophic effect. More recently, a similar role for NGF has also been established for central cholinergic neurons of the basal forebrain nuclei (cf. Korsching 1987; Thoenen et al., 1987). The evidence for such a retrograde messenger function of NGF evolved from the observation that the interruption of the retrograde axonal transport (axotomy, pharmacological transport blockade by disassembly of microtubules, or destruction of sympathetic nerve terminals by 6-hydroxydopamine) had the same effect as the neutralization of endogenous NGF by anti-NGF antibodies (cf. Levi-Montalcini and Angeletti, 1968; Greene and Shooter, 1980; Thoenen and Barde, 1980; Schwab and Thoenen, 1983). This indirect evidence has been complemented more recently by the demonstration that there is a correlation between the density of innervation and the levels of NGF (Korsching and Thoenen, 1983a) and its mRNA (Heumann et al., 1984; Shelton and Reichardt, 1984). Even within a given organ, regional differences in the density of innervation are reflected by differing levels of NGF (Barth et al., 1984) and its mRNA (Shelton and Reichardt, 1986), as, for example, in the rat iris. After the establishment of the correlation between the density of innervation and the levels of NGF and mRNA ${ }^{\mathrm{NGF}}$, two essential questions remain to be resolved: (a) which cells in the peripheral target tissues produce NGF and (b) by which mechanism(s) the synthesis of NGF is regulated.

\section{CELLULAR LOCALIZATION OF NGF SYNTHESIS}

The problem of the cellular localization of the site of synthesis of NGF was approached by the method of choice, namely, in situ hybridization. Because of the excessively small copy numbers of mRNA ${ }^{\text {NGF }}$ (less than one copy per million copies of total mRNA), it was found necessary to improve the signal-to-noise ratio of this method by using single-stranded ${ }^{35} \mathrm{~S}$-labeled cRNA or oligonucleotide probes. The use of ${ }^{35} \mathrm{~S}$-labeled probes is a compromise between ${ }^{3} \mathrm{H}$ and ${ }^{32} \mathrm{P}$ labeling. ${ }^{3} \mathrm{H}$ Labeling provides optimal resolution, but ${ }^{3} \mathrm{H}$ probes cannot be produced with a sufficiently high specific activity. ${ }^{32} \mathrm{P}$ probes provide optimal specific activities, but resolution is very poor. With improved procedures developed for ${ }^{35} \mathrm{~S}$-labeled cRNA and oligonucleotide probes (for details see Bandtlow et al., 1987), it was possible to demonstrate that in the target organs of sympathetic and neural crest-derived NGF-responsive sensory neurous, a great 
variety of cells produces NGF, including epithelial cells, smooth muscle cells, fibroblasts, and Schwann cells. In the peripheral target areas the Schwann cells which ensheath the fibers of NGF-responsive neurons represent only a relatively small proportion of the total cell number (for example, $4-5 \%$ in the iris), supporting the concept that sympathetic and sensory neurons rely on their peripheral target cells, rather than ensheathing Schwann cells, for their supply of NGF (see also below).

\section{POSSIBLE MECHANISMS INVOLVED IN NGF SYNTHESIS}

In order to prove the mechanism(s) by which NGF synthesis is regulated, two approaches were used: (a) an analysis of the appearance of NGF and its mRNA during embryonic development, and how it correlated with the ingrowth of nerve fibers of NGF-responsive neurons, and (b) an analysis of the changes in NGF synthesis during experimentally induced degeneration and regeneration.

\section{Developmental Changes}

We chose the mouse whisker pad to analyze the relationship between the ingrowth of the sensory nerve fibers and the development of NGF and mRNA ${ }^{\mathrm{NGF}}$ levels in their target areas (Davies et al., 1987). The ingrowth of sensory nerve fibers from the trigeminal ganglion into the maxilla occurs within a well-defined and precisely timed schedule (Davies and Lumsden, 1984). The ingrowing sensory fibers do not intermingle with the other nerve fibers from autonomic neurons or motoneurons. The time-course studies of the innervation of the maxilla (which later develops to the whisker pad) and the corresponding changes in the levels of NGF and mRNA ${ }^{\mathrm{NGF}}$ were complemented by the determination of the time course of the expression of NGF receptors on the ingrowing trigeminal nerve fibers (Davies et al., 1987). Interestingly, by embryonic day (E10), when the mouse trigeminal sensory nerve fibers started to grow into the maxillary process, they still had not yet expressed any NGF receptors. The fibers began to express NGF receptors only when the first fibers reached the epithelial layer of the maxillary process (E11). The appearance of the first detectable levels of mRNA $^{\mathrm{NGF}}$, immediately followed by corresponding levels of NGF, also coincided with this arrival of the sensory nerve fibers in the target areas. The levels of $\mathrm{mRNA}^{\mathrm{NGF}}$ and NGF increased concomitantly with the increasing density of nerve fibers and with the development of the maxillary process into the whisker pad with its differentiated structures, in particular the hair follicles (Davies et al., 1987). The mRNA ${ }^{\mathrm{NGF}}$ remained at elevated levels, whereas those of NGF started to decline just at the time when the density of the ingrowing sensory nerve fibers began to increase (E13). Coincidant with the decrease in the levels of NGF in the whisker pad, there was a corresponding increase in the NGF levels in the trigeminal ganglion, in which $\mathrm{mRNA}^{\mathrm{NGF}}$ levels never reached the detection limit. This strongly suggested that the NGF present in the developing trigeminal ganglion results from retrograde transport rather than from local synthesis. 
Because the onset of NGF synthesis did not precede the arrival of sensory fibers in the target area, and the trigeminal fibers initially did not express NGF receptors, it can be concluded that the ingrowth of the sensory fibers into the maxillary process is not regulated by any chemotactic action of NGF. This is further evidence for the concept that NGF comes into play at a relatively advanced stage of neuronal development, being available in limited quantities and regulating the density of innervation and the extent of neuronal survival in a competitive manner (cf. Barde et al., 1987).

The time course of the ingrowth of trigeminal nerve fibers into the whisker pad and the time course of the synthesis of mRNA $^{\text {NGF }}$ and NGF are compatible with the hypothesis that the ingrowing nerve fibers initiate the synthesis of NGF in the target areas. The main increase occurred in the epithelial layer, where NGF levels were about 10 times higher than in the underlying mesenchyme (Davies et al., 1987). The question of whether ingrowing nerve fibers trigger NGF synthesis is currently being investigated in the chick embryo, where the sensory input to the skin can be eliminated by removal of the neural tube and/or the neural crest at early developmental stages. Preliminary experiments indicate that the time course and the extent of developmental changes in mRNA ${ }^{\text {NGF }}$ levels in the skin of the chick leg are independent of the neuronal input, implying a precisely timed endogenous "clock," the nature of which remains to be established.

\section{Lesion of the Rat Sciatic Nerve; Changes of NGF Synthesis in Nonneuronal Cells}

In the adult rat sciatic nerve, nonneuronal cells do not contribute substantially to the NGF supply required by responsive sympathetic and dorsal root sensory neurons projecting to the periphery. This is reflected by the high ratio of NGF to mRNA ${ }^{\text {NGF}}$, in contrast to densely innervated peripheral organs, which have NGF levels similar to those in the sciatic nerve (Heumann et al., 1987). The high NGF levels in the sciatic nerve result predominantly from NGF transported retrogradely from peripheral target tissues (Korsching and Thoenen, 1983b; Heumann et al., 1987). However, after transection of the sciatic nerve, local synthesis by nonneuronal cells increases up to 15 -fold both proximally and distally to the transection site. Distal to the transection site $\mathrm{mRNA}^{\mathrm{NGF}}$ levels increased in all segments investigated, whereas proximally the increase in $\mathrm{mRNA}^{\mathrm{NGF}}$ was restricted to the very end of the nerve stump, which acts as a "substitute target organ" for regenerating NGF-responsive nerve fibers. The mRNA ${ }^{\mathrm{NGF}}$ levels in the nerve stump correspond to those in a densely innervated peripheral organ. However, the amount of tissue is too small to replace fully the interrupted supply from the periphery. In situ hybridization experiments demonstrated that after transection, all nonneuronal cells expressed mRNA ${ }^{\mathrm{NGF}}$, and not just those ensheathing the NGF-responsive neurons (Bandtlow et al., 1987; Heumann et al., 1987). When pieces of rat sciatic were brought into culture, the mRNA ${ }^{\text {NGF }}$ levels first increased to a maximum after $8 \mathrm{hr}$, and then dropped to lower levels between 12 and $24 \mathrm{hr}$, just as they do in vivo (Heumann et al., 1987). However, in contrast 
to the further increases seen on the following days in vivo, the mRNA ${ }^{\mathrm{NGF}}$ levels in the sciatic organ cultures remained only slightly elevated, similar to the time course of mRNA ${ }^{\mathrm{NGF}}$ levels in cultured rat iris (Heumann and Thoenen, 1986). Since the major difference between the preparations in vivo and those in vitro is the immigration of macrophages in vivo into the lesion site, we investigated the effect of the addition of activated macrophages to the in vitro sciatic nerve. The addition of macrophages, indeed, resulted in a prolonged increase in the levels of mRNA $^{\mathrm{NGF}}$ present, mimicking the situation in vivo. Preliminary experiments have demonstrated that it is not the presence of activated macrophages as such that is necessary and that their conditioned medium is sufficient. The identification of the secretory products of macrophages responsible for the regulation of synthesis of NGF is currently under investigation.

\section{REFERENCES}

Bandtlow, C. E., Heumann, R., Schwab, M. E., and Thoenen, H. (1987). Cellular localization of nerve growth factor synthesis by in situ hybridization. EMBO J. 6:891-899.

Barde, Y.-A., Davies, A. M., Johnson, J. E., Lindsay, R. M., and Thoenen, H. (1987). Brain derived neurotrophic factor. Prog. Brain Res. 71: 185-189.

Barth, E. M. Korsching, S., and Thoenen, H. (1984). Regulation of nerve growth factor synthesis and release in organ cultures of rat iris. J. Cell Biol. 99:839-843.

Cowan, W. M., Fawcett, J. W., O'Leary, D. D. M., and Stanfield, B. B. (1984). Regressive Events in Neurogenesis. Science 225:1258-1265.

Davies, A., and Lumsden, A. (1984). Relation of target encounter and neuronal death to nerve growth factor responsiveness in the developing mouse trigeminal ganglion. J. Comp. Neurol. 223:124-137.

Davies, A. M., Bandtlow, C., Heumann, R., Korsching, S., Rohrer, H., and Thoenen, H. (1987). Timing and site of nerve growth factor synthesis in developing skin in relation to its innervation and expression of the receptor. Nature 326:353-358.

Greene, L. A., and Shooter, E. M. (1980). The nerve growth factor: Biochemistry, synthesis, and mechanism of action. Ann. Rev. Neurosci. 3:353-402.

Heumann, R., and Thoenen, H. (1986). Comparison between the time course of changes in nerve growth factor (NGF) protein levels and those of its messenger RNA in the cultured rat iris. $J$. Biol. Chem. 261:9246-9249.

Heumann, R., Korsching, S., Scott, J., and Thoenen, H. (1984). Relationship between levels of nerve growth factor (NGF) and its messenger RNA in sympathetic ganglia and peripheral target tissues. EMBO J. 3:3138-3189.

Heumann, R., Korsching, S., Bandtlow, C., and Thoenen, H. (1987). Changes of nerve growth factor synthesis in nonneuronal cells in response to sciatic nerve transection. J. Cell Biol. 104:16231631.

Korsching, S. (1987). The role of nerve growth factor in the CNS. TINS 12:570-573.

Korsching, S., and Thoenen, H. (1983a). Nerve growth factor in sympathetic ganglia and corresponding target organs of the rat: Correlation with density of sympathetic innervation. Proc. Natl. Acad. Sci. USA 80:3513-3516.

Korsching, S., and Thoenen, H. (1983b). Quantitative demonstration of the retrograde axonal transport of endogenous nerve growth factor. Neurosci. Lett. 39:1-4.

Levi-Montalcini, R., and Angeletti, P. U. (1968). Nerve growth factor. Physiol. Rev. 48:534-569.

Schwab, M. E., and Thoenen, H. (1983). Retrograde axonal transport. In Handbook of Neurochemistry Vol. 5 (A. Lajtha, Ed.), Plenum, New York, London, pp. 381-404.

Shelton, D. L., and Reichardt, L. F. (1984). Expression of the nerve growth factor gene correlates with the density of sympathetic innervation in effector organs. Proc. Natl. Acad. Sci. USA 81:7951-7955.

Shelton, D. L., and Reichardt, L. F. (1986). Studies on the regulation of beta-nerve growth factor gene expression in the rat iris: The level of mRNA-encoding nerve growth factor is increased in 
irises placed in explant cultures in vitro, but not in irises deprived of sensory or sympathetic innervation in vivo. J. Cell Biol. 102:1940-1948.

Thoenen, H., and Barde, Y. A. (1980). Physiology of nerve growth factor. Physiol. Rev. 60:1284-1335.

Thoenen, H., and Edgar, D. (1985). Neurotrophic factors. Science 229:238-242.

Thoenen, H., Bandtlow, C., and Heumann, R. (1987). The physiological function of nerve growth factor in the central nervous system: Comparison with the periphery. Rev. Physiol. Biochem. Pharmacol. 109:145-178. 